1. MBBS, M.Phil (Biochemistry) Lecturer Biochemistry Bahria University Medical and Dental College, Karachi, Pakistan.

2. MBBS, FCPS

Assistant Professor Nephrology Jinnah Post Graduate Medical Center, Karachi, Pakistan.

3. MBBS, MCPS, DPH, DDM, DME Professor Medicine Sharif Medical and Dental College, Lahore, Pakistan.

4. MBBS, M.Phil (Anatomy) Assistant Professor Anatomy Liaquat National Hospital \& Medical College, Karachi.

5. MBBS, FCPS

Assistant Professor Nephrology Pir Syed Abdul Qadir Shah Jillani Institute of Medical Sciences, Pakistan.

6. MBBS, FCPS

Assistant Professor Gastroenterology

Pir Syed Abdul Qadir Shah Jillani Institute of Medical Sciences, Pakistan.

Correspondence Address:

Dr. Sadia Rehman

Flat No E-12, Nore 2 (Naval Officers Residential Estate 2),

Behind Ayesha Bawani School, Shahra e Faisal, Karachi, Pakistan. dr.sadia89@hotmail.com

Article received on: 23/09/2019 Accepted for publication: $07 / 12 / 2019$

\section{IMPACT OF DURATION OF HEMODIALYSIS ON LIPID PROFILE IN END STAGE RENAL DISEASE PATIENTS RECEIVING HEMODIALYSIS.}

\author{
Sadia Rehman', Santosh Kumar², Fatima Mehboob³, Fatima Rehman ${ }^{4}$, Syed Hidayat Ali ${ }^{5}$, \\ Kapeel Raja ${ }^{6}$
}

ABSTRACT... End Stage Renal Disease (ESRD) patients receiving hemodialysis are at a higher risk of developing dyslipidemia which is undoubtedly a predisposing factor of cardiac related disease in these patients. Objectives: To assess serum lipid profile in subjects having end stage renal disease and receiving maintenance hemodialysis and to compare it with normal healthy controls and also to assess the effects of duration of hemodialysis on the lipid profile. Study Design: Case-control study. Setting: Executed in the Nephrology Department of JPMC. Period: January 2018 to January 2019. Material and Methods: Blood samples were obtained from a total of 90 subjects. Subjects were stratified into 3 groups including cases of ESRD receiving maintenance hemodialysis and matched healthy controls. Analysis for serum triglyceride, serum VLDL, total cholesterol, LDL and HDL was done. Results: A significant rise in serum triglyceride content and total serum cholesterol of hemodialysis patients $(p<0.01$ ) was detected as compared to healthy controls. A statistically significant decrease was found in serum HDL level $(p<0.01)$ in hemodialysis patients in comparison to healthy controls. The impact of the hemodialysis duration was found to deteriorate the lipid profile of patients having longer duration of hemodialysis. Conclusion: Dyslipidemia was found to be evident in hemodialysis patients. The duration of hemodialysis sessions was found to affect the lipid profile of ESRD patients, which may play a role in higher incidence of atherosclerotic related cardiac events among these patients.

Key words: $\quad$ Chronic Kidney Disease, Dyslipidemia, End Stage Renal Disease, Hemodialysis.

\section{INTRODUCTION}

Hemodialysis is a contemporary procedure used for patients of acute and end stage renal disease to get rid of excess body fluid and waste products from blood. Dialysis-related pathology (DRP) is observed as a side effect in patients on longer duration of hemodialysis and is becoming a big concern for the nephrologists as it is the most common cause of morbidity and mortality after 15 years of hemodialysis. ${ }^{2}$

ESRD is confirmed when the presence of estimated GFR $<15 \mathrm{~mL} / \mathrm{min} / 1.73 \mathrm{~m}^{3}{ }^{3,4}$ The annual incident figures of upcoming cases of ESRD in Pakistan were determined to be $>100 /$ million in the general population (Saeed et al.,2012).
Among many other diseases worldwide, CKD has been considered as a distressing public health condition. For CKD patients particularly, who have progressed into ESRD, the potential hazards of all-cause mortality and cardiovascular incidents are significantly increased compared to the individuals with normal kidney function. ${ }^{6}$ Several reports have labeled cardiovascular episodes as a prime source of the increased morbidity and mortality in ESRD patients undergoing hemodialysis. ${ }^{7,8}$ The traditional causes are hypertension, diabetes, hyperlipidemia, and factors originating from the renal disease and the dialysis procedure itself. 7,9

CKD patients commonly develop dyslipidemia even before starting the hemodialysis procedure 
and the rate of lipid profile imbalance depends upon the extent of renal function deterioration and the levels of proteinuria. Dyslipidemia in CKD patients who are not having significant proteinuria and in patients of ESRD receiving maintenance hemodialysis, is characterized by elevated serum triglycerides, an increase in plasma levels of very low density lipoproteins(VLDL), elevated levels of oxidized lipoproteins, decreased concentration of high density lipoprotein cholesterol (HDL-C) levels. ${ }^{10}$ In contrast to the patients having significant proteinuria who have hypercholesterolemia, the ESRD patients maintained on hemodialysis and the CKD patients not having nephrotic-range proteinuria the serum cholesterol and low density lipoprotein cholesterol (LDL-C) values are usually below or within the normal limits. ${ }^{10}$ Moreover, their LDL is highly atherogenic because of the occurrence of oxidative changes. ${ }^{10}$ Hence, the classical picture of lipid levels in advanced stage kidney disease is hypertriglyceridemia, reduced HDL-C with low to normal levels of LDL-C. ${ }^{11}$

Dyslipidemia leads to atherosclerosis which is potentially a serious condition in which fat particles called plaques get lodged in arterial walls making them stiff and narrow, thus increasing the chances of cardiovascular disease. ${ }^{12,13}$ Prolonged hemodialysis causes reduced levels of HDL-C and hence leads to development and progression of atherosclerosis in these patients. ${ }^{14}$

The objectives of this study were to assess dyslipidemia and comparing lipid profiles of hemodialysis patients having end stage renal disease with healthy control group and also to assess the effect of duration of hemodialysis on lipid profile. Hence, this will give an insight into prompt detection of risk factors and protection against the cardiac events that take place in ESRD patients and thus help in decreasing the morbidity and mortality in this group of patients.

\section{MATERIAL \& METHODS}

This case-control, hospital based study recruited patients of ESRD from the Nephrology Department of Jinnah Post Graduate Centre (JPMC) Karachi during the period of January 2018 - January 2019. Individuals of either sex ( $<18$ years old) undergoing dialysis for over more than 2 months and not taking supplementary antioxidants were included. Patients suffering from any other chronic illness e.g tuberculosis, diabetes or malignancy, patients undergoing hemodialysis with acute renal failure, patients receiving statin therapy and all subjects who were not willing to participate in the study were excluded.

A total of 90 selected individuals were divided into three groups as accordingly:

Group A Included 30 Healthy controls, Group $B$ Included 30 subjects receiving hemodialysis therapy for more than 2 months but less than 3 years and Group C Included 30 subjects receiving hemodialysis for more than 3 years (maximum duration 10 years).

Ethical permission for the present study was taken from the Institutional Review Committee JPMC, Karachi dairy no:NO.F.2-81-IRB/2018GENL/5173/JPMC. All the subjects gave written informed consent.

Data collection included age, gender, weight, height, body mass index (BMI) and hemodialysis duration. Blood pressure (BP) and drug history were also noted. Venous blood samples were collected after overnight fasting. After centrifugation at 3000 rotations/minute for 10 minutes, separated serum was collected from the centrifuge tubes and transferred into aliquot tubes under aseptic conditions. Each tube was labeled with patient identification number and kept at $-20^{\circ} \mathrm{C}$ until analyzed. Serum analysis was done for serum triglycerides (mg/dl), total serum cholesterol (mg/dl), HDL-cholesterol $(\mathrm{mg} / \mathrm{dl})$ and VLDL $(\mathrm{mg} / \mathrm{dl})$ by enzymatic colorimetric method while LDL-cholesterol (mg/dl) was calculated by Friedewald's Formula (LDL-C $=\mathrm{TC}-\mathrm{TG} / 5-$ HDL-C). ${ }^{15}$

Statistical analyses of recorded data was done using IBM SPSS version 23. Descriptive analysis of the categorical data was shown as frequency and percentages while the continuous variables were described as mean and standard deviation, P-value of $<0.05$ was considered to be significant. 


\section{RESULTS}

The general clinical and demographic data are presented in Table-l. Age was found to be insignificant. Maximum decrease in BMI was seen in group $\mathrm{C}$. Hemodialysis patients of group $\mathrm{B}$ and $C$ had higher SBP and DBP as compared to the subjects of control group.

Comparison of all serum parameters between groups showed significantly higher TG levels in group $C$ (subjects on longer duration of hemodialysis) as compared to group A and B, serum cholesterol found higher but within normal limits in group B and decreased as the duration of dialysis increased, HDL found significantly

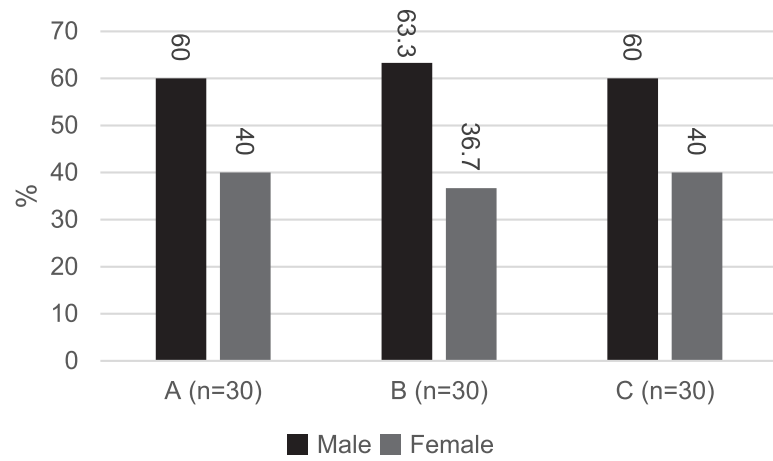

Bar chart showing distribution of samples with respect to gender

\begin{tabular}{|c|c|c|c|c|c|c|c|}
\hline \multirow{3}{*}{ Characteristics } & \multicolumn{6}{|c|}{ Group } & \multirow{3}{*}{ P-Value } \\
\hline & \multicolumn{2}{|c|}{$A(n=30)$} & \multicolumn{2}{|c|}{$B(n=30)$} & \multicolumn{2}{|c|}{$C(n=30)$} & \\
\hline & Mean & SD & Mean & SD & Mean & SD & \\
\hline BMI (kg/m2) & 23.47 & 3.26 & 22.60 & 3.72 & 20.21 & 4.21 & $<0.01^{*}$ \\
\hline Systolic Blood Pressure (mmHg) & 107.33 & 9.80 & 135.33 & 11.06 & 159.00 & 12.42 & $<0.01^{*}$ \\
\hline Diastolic Blood Pressure (mmHg) & 66.33 & 8.09 & 87.57 & 8.84 & 93.67 & 10.66 & $<0.01^{*}$ \\
\hline Height (m) & 1.69 & 0.12 & 1.64 & 0.11 & 1.63 & 0.12 & 0.20 \\
\hline Duration of Dialysis (years) & Nil & Nil & 1.70 & 0.69 & 7.72 & 1.71 & $<0.01^{*}$ \\
\hline
\end{tabular}

Table-I. Comparison of anthropometric measurements among study groups:

\begin{tabular}{|c|c|c|c|c|c|c|c|}
\hline \multirow{3}{*}{ Serum Parameters } & \multicolumn{6}{|c|}{ Group } & \multirow{3}{*}{ P-Value } \\
\hline & \multicolumn{2}{|c|}{$A(n=30)$} & \multicolumn{2}{|c|}{$B(n=30)$} & \multicolumn{2}{|c|}{$C(n=30)$} & \\
\hline & Mean & SD & Mean & SD & Mean & SD & \\
\hline TG (mg/dl) & 87.90 & 22.24 & 134.97 & 27.57 & 182.07 & 21.80 & $<0.01^{\star}$ \\
\hline VLDL(mg/dl) & 23.19 & 6.51 & 35.59 & 3.91 & 42.32 & 6.14 & $<0.01 *$ \\
\hline Cholesterol (mg/dl) & 103.77 & 19.58 & 138.80 & 38.85 & 115.07 & 38.84 & $<0.01 *$ \\
\hline $\mathrm{HDL}(\mathrm{mg} / \mathrm{dl})$ & 44.13 & 6.61 & 31.50 & 4.27 & 21.63 & 4.75 & $<0.01^{*}$ \\
\hline LDL (mg/dl) & 72.90 & 12.25 & 87.70 & 17.71 & 73.00 & 13.68 & $<0.01^{*}$ \\
\hline
\end{tabular}

Professional Med J 2020;27(6):1230-1236.

www.theprofesional.com

1232 


\begin{tabular}{|c|c|c|c|c|c|c|c|}
\hline \multirow{2}{*}{ Serum Parameters } & \multicolumn{6}{|c|}{ Group } & \multirow{2}{*}{ P-Value } \\
\hline & Mean & SD & Mean & SD & Mean & SD & \\
\hline TG:HDL (unit) (ratio has no units) & 2.03 & 0.60 & 4.34 & 0.94 & 8.83 & 2.24 & $<0.01^{*}$ \\
\hline
\end{tabular}

\section{DISCUSSION}

Kidney failure patients presents with higher chances of cardiovascular associated morbidity and mortality than the general population. Dialysis patients have 30 times higher risk of cardiac related mortality rate than general public and stays on higher scale even after adjusting for age, gender, and diabetes presence. ${ }^{16}$

We have not found marked difference of the mean ages in between the three groups compared at $95 \%$ confidence interval. However, our study revealed a statistically significant reduction in BMl among cases as compared to controls, which is in accordance with a study done on maintenance hemodialysis patients that showed that body weight of individuals on maintenance hemodialysis was lower as compared to normal individuals. ${ }^{17}$

We have found a remarkable increase in levels of serum TG and VLDL in hemodialysis patients as compared to control group with a significant rise in levels as the duration of dialysis progresses. Past data has revealed that compromised kidney function seriously affect the levels of triglycerides and VLDL even in those patients who present with normal levels of serum creatinine..$^{8,18,19}$ In ESRD patients, the start of renal replacement therapy and the type dialysis procedure distinctly affect the levels of apolipoproteins. ${ }^{20}$ Factors which are associated with the hemodialysis technique evidently increase the levels of triglycerides in these patients. Dialysis procedure requires routine administration of low-molecular weight heparins to prevent blood coagulation during the ongoing process, this may be the cause of disturbed metabolism of Triglyceride related lipoproteins as heparin causes the loss of lipoprotein lipase enzyme by the endothelialcells, therefore, long term heparin use contributes in deficiency of lipase enzyme. ${ }^{14}$
A significant decrease was seen in serum HDL levels as the duration of dialysis increased. Several prior studies have ascertained the low antioxidant action of HDL in patients of long term dialysis as compared to the HDL of the healthy controls. ${ }^{23}$

We have found a significant difference in the total serum cholesterol and LDL-C levels in group $B$ as compared to control group. However in group C the levels of TC and LDL were a little decreased as compared to group $B$. These findings reflect the observations of Moradiet al. ${ }^{10}$, Visconti et al. ${ }^{18}$ and Samouilidou et al. ${ }^{24}$ who also repor ted a decrease in levels of TC and LDL as the duration of therapy progressed. This is probably due to the fact thatpatients who undergo hemodialysis have a higher risk of being influenced by changes in their nutritional status as a result of disease related anorexia,alteration in diet, physical inactivity, presence of chronic inflammation, comorbid conditions, and altered metabolism. ${ }^{25,26}$ Moreover, majority of CRF patients receiving hemodialysis presents with muscle wasting due to protein-energy malnutrition which might be another reason for decrease in total cholesterol levels. ${ }^{27}$

Our findings are in accordance to the published work of Moradi et al. who reported deranged lipid profilewith less signs of proteinuria in majority of CKD patients. They further concluded high levels of triglycerides, accumulation of oxidized lipids and lipoproteins and decreased levels of high density lipoprotein (HDL) levelsin ESRD patients on hemodialysis. Thus, deranged lipid metabolism appears to be the main contributing factor in influencing the systemic inflammatory process and oxidative stress and ultimately becoming the source of high cardiovascular accidents and overall health distress and fatality rate in this population. ${ }^{10}$ 
We also recorded a statistically higher Triglyceride/HDL ratio in group $B$ and $C$ as compared to controls. In consistence to our finding, Lee et al. ${ }^{28}$ and Chen with co-workers ${ }^{29}$ also reported high TG/HDL ratio in patients treated by hemodialysisand reported its association with high cardiovascular risk index. It has been estimated that $\mathrm{TG} / \mathrm{HDL}$ ratio of $>3.8$ indicates the presence of small atherogenic LDL particles which are the prime sources of atherosclerotic lesions in vessels, thus leading to increased risk of cardiac abnormalities. ${ }^{29}$

The duration of hemodialysis was found to effect the level of serum lipids. Patients having upto 3 or more than 3 years of duration showed higher TG and VLDL, within normal cholesterol levels and lower HDL concentrations than patients dialyzed for less than 3 years. This is in concordance with the work of Cofan, who analyzed dyslipidemia in patients on chronic hemodialysis and concluded that duration of hemodialysis has adverse effects on lipid profile of such patients. ${ }^{30}$

\section{CONCLUSION}

In the current study it can be concluded that dyslipidemia is common among ESRD patients on hemodialysis and its magnitude increases with longer duration of hemodialysis in ESRD patients receiving maintenance hemodialysis.

\section{Conflict of Interest}

There is no conflict of interest between the authors.

\section{Copyright@ 07 Dec, 2019.}

\section{REFERENCES}

1. Lee MJ, Park JP, Han SH, Kim Y, Kim YS, Yang CW, Kim $\mathrm{N}$, Kang S, Kim HJ, Yoo T. The atherogenic index of plasma and the risk of mortality in incident dialysis patients: Results from a nationwide prospective cohort in Korea. PLoS ONE 2017; 12(5): e0177499. https://doi.org/10.1371/journal. pone.0177499.

2. Tanaka K, Yao T, Fujimura T, Murayama K, Fukuda S, Okumura K, Seko Y. Marked elevation of plasma levels of oxidative stress-responsive apoptosisinducing protein in dialysis patients. Kidney Intern Reports. 2016; 1(4):321-324.
3. Levey AS, Eckardt KU, Tsukamoto Y, Levin A, Coresh J, Rossert $J$ and Eknoyan, G. Definition and classification of chronic kidney disease: A position statement from Kidney Disease: Improving Global Outcomes (KDIGO). Kidney Intern., 2005; 67(6):2089-2100.

4. Webster AC, Nagler EV, Morton RL, Masson P. Chronic kidney disease. The Lancet, 2017; 389(10075):123852.

5. Saeed ZI and Hussain SA. Chronic kidney disease in Pakistan: An under-recognized public health problem. Kidney International, 2012; 81(11):1151.

6. Zhou L, Zeng XX, Fu P. Community hemodialysis in China: Opportunities and challenges. Chinese Med J., 2017; 130:2143-6.

7. Spittle M, Hoenich NA, Handelman G, Adhikarla R, Homel P, Levin NW. Oxidative stress and inflammation in hemodialysis patients. Am J Kidney Dis., 2001; 38(6):1408-1413.

8. Chang TI, Streja E, Soohoo M, Kim TW, Rhee CM, Kovesdy CP. and Moradi H. Association of Serum Triglyceride to HDL cholesterol ratio with all-cause and cardiovascular mortality in incident hemodialysis patients. Clin J Am SocNephrol., 2017; 12(4):591-602.

9. Förstermann $\mathrm{U}$, Xia $\mathrm{N} \& \mathrm{Li} \mathrm{H}$. Roles of vascular oxidative stress and nitric oxide in the pathogenesis of atherosclerosis. Circulation Res., 2017; 120(4):713735 .

10. Moradi H \&Vaziri ND. Molecular mechanisms of disorders of lipid metabolism in chronic kidney disease. FrontBiosci (Landmark Ed). 2018; 23:146-161.

11. Hager MR, Narla AD \&Tannock LR. Dyslipidemia in patients with chronic kidney disease. Rev Endocr Metab Disord., 2016; DOI 10.1007/s11154-016-9402-z.

12. Gao S., Zhao D., Wang M., Zhao F., Han X., Qi Y. \& Liu J. Association between circulating oxidized LDL and atherosclerotic cardiovascular disease: A meta-analysis of observational studies. Canadian $\mathrm{J}$ Cardiol., 2017; 33(12):1624-1632.

13. Gepner AD, Young R, Delaney JA, Tattersall MC, Blaha MJ, Post WS.\& Folsom AR. Comparison of coronary artery calcium presence, carotid plaque presence, and carotid intima-media thickness for cardiovascular disease prediction in the multi-ethnic study of atherosclerosis clinical perspective. Circ Cardiovas Imaging, 2015; 8(1):e002262.

14. Tsimihodimos V, Mitrogianni Zand Elisaf M. Dyslipidemia associated with chronic kidney disease. Open CardiovasMedJ., 2011, 5, 41-48 41, 1874-1924/11 2011. 
15. Friedewald WT, Levy RI, Fredrickson DS. Estimation of the concentration of low density lipoprotein cholesterol in plasma, without use of the preparative ultracentrifuge. Clin Chem., 1972; 18(6):499-502.

16. Arici $M$ \& Walls J. End-stage renal disease, atherosclerosis, and cardiovascular mortality: Is C-reactive protein the missing link?. Kidney Intern., $2001 ; 59(2): 407-414$.

17. Kopple JD, Zhu X, Lew NL and Lowrie EG. Body weight-for-height relationships predict mortality in maintenance hemodialysis patients. Kidney International, 1999; 56:1136-1148.

18. Visconti L, Benvenga S, Lacquaniti A, Cernaro V, Bruzzese A, Conti G and Santoro D. Lipid disorders in patients with renal failure: Role in cardiovascular events and progression of chronic kidney disease. J Clin Translational Endocrinol., 2016; 6:8-14.

19. Reiss AB, Voloshyna I, De Leon J, Miyawaki N \& Mattana J. Cholesterol metabolism in CKD. AmJ Kidney Dis., 2015; 66(6):1071-1082.

20. Attman PO, Samuelsson O, Johansson AC, Moberly JB, Alaupovic P. Dialysis modalities and dyslipidemia. Kidney Intern. 2003; 63:S110-2.

21. Shearer GC, Stevenson FT, Atkinson DN, Jones Jr $H$, Staprans I, Kaysen GA. Hypoalbuminemia and proteinuria contribute separately to reduced lipoprotein catabolism in the nephrotic syndrome. Kidney Intern., 2001;59(1):179-89.

22. Moradi H, Streja E, Kashyap ML, Vaziri ND, Fonarow GC, Kalantar-Zadeh K. Elevated high-density lipoprotein cholesterol and cardiovascular mortality in maintenance hemodialysis patients. Nephrol Dialysis Transplant., 2014; 29(8):1554-62.

23. Moradi H, Pahl MV, Elahimehr R, Vaziri ND. Impaired antioxidant activity of high-density lipoprotein in chronic kidney disease. Translational Research. 2009; $1 ; 153(2): 77-85$.

24. Samouilidou EC, Karpouza AP, KostopoulosV, Bakirtzi T, Pantelias K, Petras D.\& Grapsa E. Lipid abnormalities and oxidized LDL in chronic kidney disease patients on hemodialysis and peritoneal dialysis. Renal Failure, 2012; 34(2):160-164.
25. Ikizler TA, Cano NJ, Franch H, Fouque D, Himmelfarb J, Kalantar-Zadeh K. \& Wang AYM. Prevention and treatment of protein energy wasting in chronic kidney disease patients: A consensus statement by the International Society of Renal Nutrition and Metabolism. Kidney Intern., 2013; 84(6):1096-1107.

26. Araujo JTDCA, Assis MG, Felipe TR, Pinto EF, Luiz R, Fagundes MC and da Mata N. Body composition, quality of life, lipid profile, and physical fitness in patients with chronic kidney disease in hemodialysis. J Exercise Physiol Online, 2017; 20(6):102-116.

27. Rafferty A, Wang L, Parsons T, Gray V \& Reiboldt W. Effect of dietary education and high energy/protein meals on lean body mass during hemodialysis treatment in hypoalbuminemic hemodialysis patients. The FASEB J., 2016; 30(1suppl):Ib222-lb222.

28. Lee T, Mokrzycki M, Moist L, Maya I, Vazquez M, Lok CE. Standardized definitions for hemodialysis vascular access. Seminars in Dialysis 2011; 24(5):515-524).

29. Chen H, Tsai W, Chiu Y, Hsu S, Pai M, Yang J and Peng Y. Triglyceride to high-density lipoprotein cholesterol ratio predicts cardiovascular outcomes in prevalent dialysis patients. Medicine, 2015; 94(10):15 pages. DOl:10.1097/MD.0000000000000619.

30. Cofan F, Vela E, Cleries $\mathbf{M}$ and collaborative study group for dyslipidemia. Analysis of dyslipidemia in patients on chronic hemodialysis in Catalonia. Atherosclerosis, 2006; 184:94-102.

31. Bansal N, McCulloch CE, Lin F, Alper A, Anderson $\mathrm{AH}$, Cuevas M, Go AS, Kallem R, Kusek JW, Lora CM, Lustigova E, Ojo A, Rahman $M$, RobinsonCohen C, Townsend RR, Wright J, Xie D, Hsu C and CRIC study investigators. Blood pressure and risk of cardiovascular events in patients on chronic hemodialysis The CRIC study (Chronic renal insufficiency cohort). Hypertension. 2017; 70:435-443.

32. Maheshwari N, Ansari MR, Laghari MS, Lal K, Ahmed $\mathrm{K}$. Pattern of lipid profile in patients on maintenance hemodialysis. Saudi Journal of Kidney Diseases and Transplantation. 2010 May 1; 21(3):565. 


\begin{tabular}{|c|c|c|c|}
\hline \multicolumn{4}{|c|}{ AUTHORSHIP AND CONTRIBUTION DECLARATION } \\
\hline Sr. \# & Author(s) Full Name & Contribution to the paper & Author(s) Signature \\
\hline 1 & Sadia Rehman & Main researcher and author. & \\
\hline 2 & Santosh Kumar & Data collection \& sampling. & \\
\hline 3 & Fatima Mehboob & Data analysis \& Rediology. & \\
\hline 4 & Fatima Rehman & Statsitical analysis. & \\
\hline 5 & Syed Hidayat Ali & Sampling & \\
\hline 6 & Kapeel Raja & Literature review. & \\
\hline
\end{tabular}

